population (United States). Cancer Causes Control 2006; 17: 851-6.

13 Coory M, Baade P. Urban-rural differences in prostate cancer mortality, radical prostatectomy and prostate-specific antigen testing in Australia. Med J Aust 2005; 182: 112-15.

14 Thompson B, Baade P, Coory M, Carriere P, Fritschi L. Patterns of surgical treatment for women diagnosed with early breast cancer in Queensland, Australia. Ann Surg Oncol 2008; 15: $443-51$.

REVIEW

\title{
Anti-neutrophil cytoplasmic antibody-associated systemic vasculitis: nature or nurture?
}

\author{
P. A. Gatenby \\ Immunology Department, The Canberra Hospital and Medical School Australian National University, Canberra, Australian Capital Territory, Australia
}

\author{
Key words \\ vasculitis, anti-neutrophil cytoplasmic antibody, \\ vitamin $\mathrm{D}$, silica, genetics.

\section{Correspondence} \\ Paul A. Gatenby, Research Office, ACT Health, \\ Level 6, Bldg 10, The Canberra Hospital, PO \\ Box 11, Woden, ACT 2606, Australia. \\ Email: paul.gatenby@anu.edu.au
}

Received 10 November 2011; accepted 12 December 2011.

doi:10.1111/j.1445-5994.2011.02705.x

\begin{abstract}
This review examines the environmental and genetic contributions to the antineutrophil cytoplasmic antibody-associated systemic vasculitides. The dominant environmental risk factors appear to be silica exposure for all three syndromes, and vitamin D deficiency is strongly suggested by the latitude and ultraviolet radiation gradient observed for Wegener's granulomatosis and Churg-Strauss syndrome. Genetic factors are generally not very strong, consistent with the rarity of these conditions in children. However, multiple genetic factors, each with a relatively small effect, may combine to create a state of susceptibility towards autoimmunity. With infection as a triggering agent, it is possible to synthesise a pathogenetic hypothesis that accounts for both environmental and genetic effects in regard to both necrotising vasculitis and granuloma formation.
\end{abstract}

\section{Introduction}

Wegener's granulomatosis (WG), microscopic polyangiitis (MPA), the Churg-Strauss syndrome (CSS) make up the anti-neutrophil cytoplasmic antibody (ANCA)associated systemic vasculitides - AASV. ${ }^{1,2}$ Clear definitions have really only been available since the development of the classification criteria by the American College of Rheumatology (ACR) in $1990^{3}$ and the Chapel Hill Consensus Conference(CHCC) in $1994 .{ }^{4}$ The AASV are characterised by necrotising small-vessel vasculitis with a paucity of immune deposits seen in renal and other biopsies in association with autoantibodies to cytoplasmic proteins in neutrophils. The predominant specificity of ANCA is proteinase 3(PR3) and myeloper-

Funding: None.

Conflict of interest: None. oxidase (MPO). ${ }^{2}$ Interestingly, although most clinicians would now use ANCA to help arrive at a diagnosis, these criteria do not include ANCA, and there is probably a need for further refinement of the definitions used for research and clinical purposes. ${ }^{5}$

The AASV are of unknown aetiology, although there is growing evidence that they are autoimmune diseases, involving the adaptive immune system, both $\mathrm{T}$ and $\mathrm{B}$ cells and the innate immune system, particularly macrophages and neutrophils. The discovery of ANCA with PR3-ANCA predominating in WG and MPO-ANCA in MPA and CSS has particularly driven this view, although the evidence that ANCA per se has a pathogenetic role is greater for anti-MPO than anti-PR3.6,7 As with most autoimmune syndromes, AASV are believed to arise as a result of environmental stimuli acting on a genetically susceptible host. Onset, typically in later years, suggests that genetic factors may be modest when compared with other autoimmune diseases. ${ }^{8,9}$ 


\section{Nurture - the environment}

Environmental studies in the AASV fall into several categories. Several good epidemiological reports that have combined careful case ascertainment and standardised definitions that illustrate variation with time, season, latitude, age and ethnic differences can be considered together to provide aetiological clues. There are casecontrol studies that have specifically sought answers about factors that have been suspected. These are supported by less definitive observational associations with particular factors, reports of drug-induced disease, triggering of attacks by infection, including a more detailed analysis of a potential role of a specific microorganism, Staphylococcus aureus (S. aureus), ${ }^{10}$ and more recently, the prospect of molecular mimicry between an ANCA subtype anti-lysosomal-associated membrane protein (LAMP-2) and common bacterial adhesion FimbriaeH $\left(\right.$ FimH). ${ }^{11}$

\section{Epidemiological studies}

The published studies are summarised in Tables 1 (incidence) and 2 (prevalence). Most have used a combination of ACR or CHCC definitions as indicated, and most have involved multiple strategies to ensure accurate capture of subjects in a particular defined geographic area. Studies that preceded the use of these definitions have been excluded. Studies from both the east and west of Asia (Japan and Kuwait) report no AASV other than MPA. ${ }^{25,26}$ In the case of Japan, this appears to be a repeatable conclusion. ${ }^{33}$ The nature of case ascertainment in Kuwait may have worked against finding conditions other than AASV. The trends that emerge from these studies can be considered under a number of headings.

\section{Age, gender and ethnicity}

Overall, these studies show that the AASV occur with advancing years, with WG peaking in the middle aged to elderly with a variable but small ratio of males to females (range M:F 1.9-0.5). In the this regard, the AASV clearly differ from the female-dominated systemic autoimmune diseases - systemic lupus erythematosus, Sjogren's syndrome, scleroderma and the antiphospholipid syndrome and probably differ in terms of their pathogenesis. ${ }^{34}$

The AASV, in particular WG, are diseases of white people of European origin. This is seen and remarked upon in Europe, the USA and New Zealand (NZ). ${ }^{27,29,31}$ Specifically in France, where there is a substantial number of non-Europeans in the Departments of Greater Paris, the overall occurrence of vasculitis was half of that seen in the Europeans in the same geographic area. ${ }^{29}$
In the USA, and more particularly in New York state, African Americans and Hispanics were underrepresented in WG when compared with the population as a whole. ${ }^{31}$ In North Carolina, African Americans were very under-represented compared with the general population. ${ }^{35}$ Similarly in NZ, the rate of vasculitis among Europeans was twice that of the NZ Maoris or Asians. ${ }^{27}$

\section{Changes over time}

There is evidence suggesting an increase in incidence of AASV over the last several decades. This is particularly evident in data from Scandinavia. In the three northernmost counties of Norway, the annual incidence and prevalence of WG rose from 5.2/million (1984-1988) to $6.5 /$ million (1989-1993) to $12.0 /$ million (1994-1998). ${ }^{20}$ A similar sort of increase was seen in Sweden. ${ }^{19}$ In Germany, there appears to be an upward trend with the incidence rates and years as follows: 1998, 11/million; 1999, 9.5/million; 2000, 12/million; 2001, 12/million; 2002, 16/million. ${ }^{14}$ In Norfolk, UK, a lesser rise occurred with AASV as a whole and seems to have plateaued..$^{36}$ In south-eastern Australia, the incidence of AASV rose from 13.4 /million in 1995-1999 to $15.6 /$ million in 2000$2004 .^{24}$ Some of this increase may have followed the introduction of widespread ANCA testing and a reclassification of idiopathic crescentic glomerulonephritis to MPA, although a number of authorities believe that there is more to it than this. It will be very important to reassess the last 5 years in these studies.

\section{Fluctuations over time}

As well as a probable increase over time, some studies have peaks and troughs in the disease occurrence, every 4-5 years a peak of WG in Norway, ${ }^{20}$ similarly, every 3-5 years in central Sweden ${ }^{37}$ and every 3 years for AASV as a whole in Spain. ${ }^{18}$ The group from Norfolk have recently reported a 7-year periodicity for WG but none for MPA. ${ }^{38}$

Temporal clustering, however, has been sought and not found in other studies. ${ }^{12-15,27}$ There are as yet no explanations, such as infectious disease cycles or ultraviolet radiation (UVR) fluctuations reported to explain these findings.

\section{The season of onset}

The season of onset has been examined in several studies with conflicting results. A winter peak is evident in data from Norfolk and Sweden; ${ }^{16,19}$ this pattern is supported by hospital-based data from other sources, ${ }^{13,35,37}$ although in one study, it was really a spring/winter peak. ${ }^{39}$ Cotch 


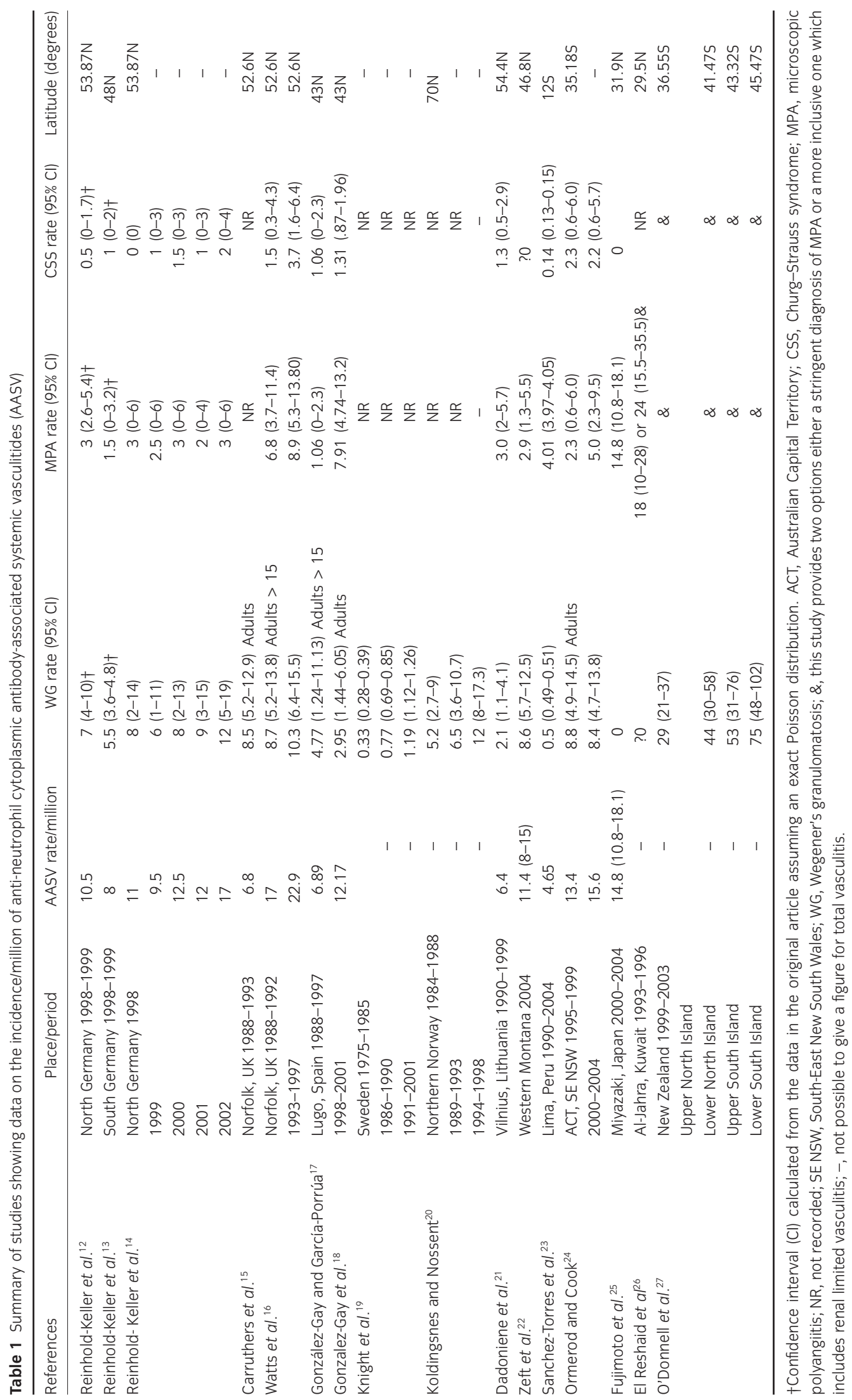




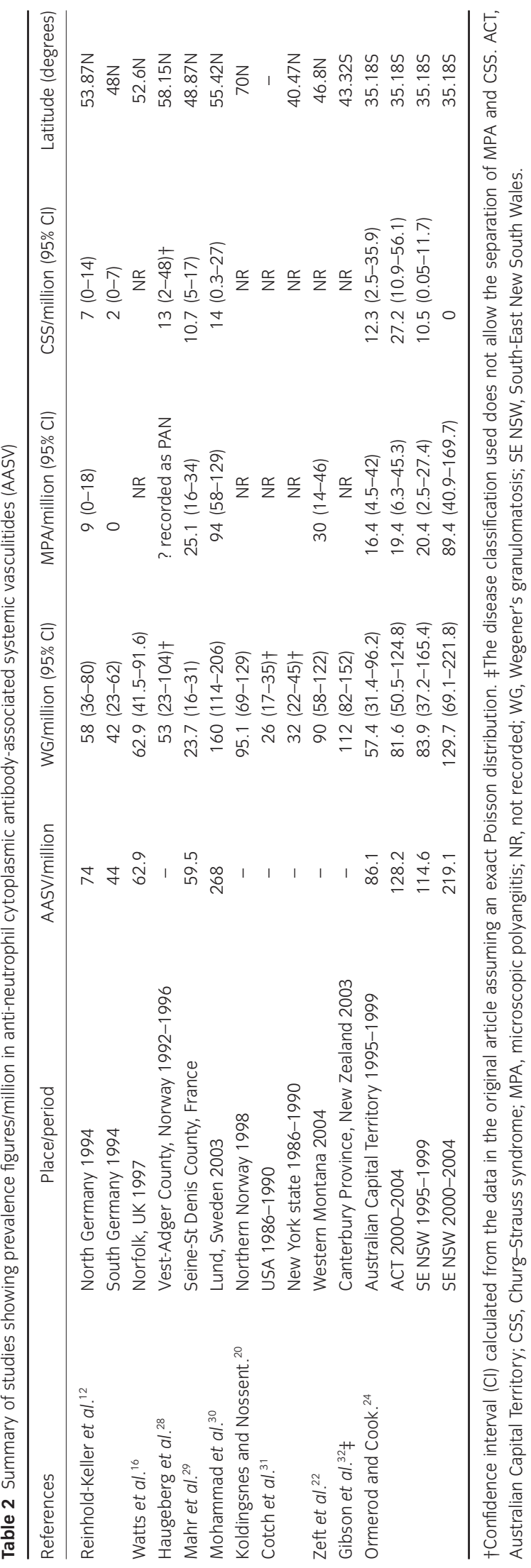

and colleagues in the USA reported an increase in autumn and spring, ${ }^{31}$ O'Donnell reported an increase in autumn and decrease in spring in their NZ series ${ }^{27}$ and a recent French survey has paradoxically shown a summer peak. ${ }^{40}$ This prompted a re-examination of the Norfolk data which now shows a non-significant winter peak, a summer trough and no relation to the serial changes in a number of important upper respiratory tract pathogens. ${ }^{41}$ While different factors may contribute to the pathogenesis in different places, providing a plausible explanation for these quite different results, several studies do not support seasonality at all. ${ }^{19,20}$ Indeed, given that patients with AASV will experience a prodromal stage to their illness of quite variable length, it is not surprising that such conflicting results are evident.

\section{Latitudinal gradient}

A latitudinal gradient exists, perhaps shown most elegantly for Caucasians of European origin in NZ, where the method of case ascertainment is identical for the whole country. ${ }^{27}$ Such a gradient is also evident in the northern hemisphere, but not as clear-cut, perhaps because of minor variations in case ascertainment or ethnic differences. ${ }^{8,9}$ The latitudinal differences in the northern hemisphere also relate to the relative frequencies of the different subsets of AASV, with WG predominating in Norway and MPA predominating in Spain and even more so in Japan and Kuwait. ${ }^{8,9}$ While ethnic differences may contribute to the latter, the differences between northern and southern Europe are unlikely to be major, and taking it with the NZ data makes it much more likely that there are environmental factors causing this.

\section{Urban-rural differences}

Most studies do not have or do not present data to address this issue, and no consistent pattern emerges. ${ }^{8,9}$

\section{Ecological study}

Using a subset of these published epidemiological studies where incident data, total population of the study region and age-specific incidence rates and study location were provided, we carried out an ecological study seeking any relationship with measures of ambient UV radiation. The latter was obtained from satellite data using the longitude and latitude of the largest urban centre in any given area. We estimated both the ambient UV radiation level weighted to erythemally effective wavelengths and to vitamin D effective wavelengths under both blue-sky and cloudy conditions. We used winter UV radiation as well 
Table 3 Regression values for the relationship between the incidence of each of the three anti-neutrophil cytoplasmic antibody-associated systemic vasculitides and ultraviolet (UV), both erythemally effective wavelengths (UV (ery) $_{\text {) }}$ and vitamin D effective wavelengths (UV(vito)

\begin{tabular}{lccc}
\hline Radiation level/diagnosis & Wegener's granulomatosis & Microscopic polyangitis & Churg-Strauss syndrome \\
\hline $\mathrm{UV}_{\text {(ery) }}$ clear & $R=-0.62, P=0.02$ & $R=-0.02, P=0.95$ & $R=-0.43, P=0.16$ \\
$\mathrm{UV}_{\text {(vit)) }}$ cloud & $R=-0.6, P=0.03$ & $R=-0.13, P=0.73$ & $R=0.48, P=0.16$ \\
\hline
\end{tabular}

There is a significant negative correlation with Wegener's granulomatosis and a strong trend in the same direction for Churg-Strauss syndrome. No relationship is seen with microscopic polyangiitis.

as mean daily ambient UV radiation because there is a stronger latitudinal gradient in winter UV radiation compared with summer UV radiation and a known limitation on vitamin D production from available winter UV radiation at high latitudes. It is noteworthy in our analysis that we were unable to use the excellent NZ data because of the nature of case ascertainment, and we excluded the data from Kuwait as we were unable to be reassured about the methods of ascertaining cases or the precise denominator population from which the study was drawn. The crude incidence rates of both CSS and WG increased with latitude, although only WG achieved statistical significance. Using a negative binomial regression, there was a modest increase in the incidence of both CSS $(3.4 \%)$ and WG $(3.5 \%)$ per a higher degree of latitude. MPA showed no association in either analysis, although it is possible that our exclusion of the data from Kuwait prevented demonstration of a previous negative correlation with latitude. ${ }^{8,9}$ The relationships were much stronger with ambient UV radiation, with a stronger inverse correlation demonstrable for WG than CSS. As expected, there was no relationship between any measure of UVR and MPA. The results are illustrated in Table 3. To give these results some perspective, the effect in both WG and CSS is of a similar magnitude to that seen with multiple sclerosis. $^{42}$

Although UVR has local effects on the immune system in the skin, ${ }^{42}$ we feel that the most plausible explanation for these findings is through the effects on vitamin D synthesis, a hormone that has profound effects on the immune system which will be further discussed later. ${ }^{43}$ Our conclusions in this regard are limited by the fact that there are no population data on vitamin $\mathrm{D}$ from the populations for which we have AASV incident data and there are no series measuring vitamin D in patients and matched controls.

\section{Case-control studies}

Case-control studies have been summarised in previous publications. ${ }^{8,9}$ These studies vary in quality, some had quite small numbers and were probably underpowered. Nevertheless, taken together, they allow a few conclu- sions. The dominant risk fact is silica, both crystalline silica and silica found in crop dusts. Silica has a major impact on the immune system, is associated with a number of autoimmune syndromes and is most commonly inhaled, so the results are not so surprising. ${ }^{44}$ The association is seen in AASV, where there is no respiratory tract disease, suggesting that the impact of silica goes beyond the immediately exposed airways. These findings are supported by other reports of silica-associated AASV, including a Japanese study from Kobe showing an increased occurrence and severity of AASV for 3 years after the devastating 1995 earthquake when compared with the unaffected neighbouring Kyoto prefecture. The authors attribute this to dust and other particulate air pollution, the dust contained silica. ${ }^{45}$ Silica, of course, is often not inhaled alone, and this needs to be borne in mind. The most interesting conclusion from the Kobe earthquake is that the environmental impact can be quite proximate, that is, the effect came and went soon after the original challenge. ${ }^{45}$ Heavy-metal exposure comes up in some studies, as do solvents and pesticides. ${ }^{8,9}$ Farming appeared an at-risk occupation in a minority of studies; farmers are probably exposed to more silica contained in dust. As has been discussed earlier, when urban and rural differences have been examined, the results are conflicting. Allergy and drug allergy (in general) appear in two of the studies., Atopy is common, allergy may be overreported and some of the clinical features, for example, sinusitis, may be seen as part of the clinical spectrum of vasculitis itself.

\section{Drug-induced vasculitis}

The earlier case-control series suggest, in some case, a general association with drug allergy without being specific. There are more specific associations, in particular, a strong case can be made that propylthiouracil (PTU) can trigger AASV. ${ }^{46}$ There are differences between the druginduced and the sporadic form of the disease, with patients showing a greater heterogeneity in renal lesions and more evidence of immune complexes than the sporadic disease. ${ }^{47}$ Some patients have recovered completely on cessation of the PTU, others have required 
conventional immunosuppressive therapy. ${ }^{46,47}$ Hydralazine has been similarly, but less frequently reported. ${ }^{48}$ The ANCA seen with the drug-induced disease appear much more heterogeneous with additional specificities, such as lactoferrin, cathepsin $\mathrm{G}$ and azurocidin and in a long list of less frequent neutrophil antigens. ${ }^{49}$

The role of certain classes of medication in precipitating CSS has been of particular concern. Thus, several postmarketing surveillance reports have appeared linking CSS to the use of leukotriene receptor antagonists (LTRA), including both cysteinyl leukotriene receptor blockers - montelukast, zafirlukast and pranlukast and zileuton, a 5-lipoxygenase inhibitor. ${ }^{50}$ Jamaleddine and colleagues analyse the literature published from 1996 to 2000, and their conclusions still stand today. ${ }^{50}$ The patients fell into three groups of roughly the same size. In one group, the patients manifest CSS without an oral steroid taper; in a second group, the onset of CSS coincided with a concomitant taper in oral corticosteroids and in the third group, the authors' opinion was that they probably already had CSS before the LTRA was begun. ${ }^{50}$ Macrolide antibiotics have been associated with CSS in a series of case reports. ${ }^{51-53}$ In most cases, it is hard to distinguish between the use of a macrolide to treat a putative respiratory tract infection in a patient already developing CSS and a true association, although one case, was preceded by an apparent positive challenge. ${ }^{53}$ Not only are the data in regard to at least some drugs still open to question, but no overall hypothesis pointing to a disease mechanism emerges from these studies.

\section{Infection}

Several observations provide limited support for infection in the primary aetiology and greater support for episodes of infection triggering relapse. ${ }^{54}$ Popa and Cohen Tervaert in Groningen ${ }^{10}$ have examined the role of S.aureus in triggering relapses and have explored possible mechanisms of action. Their work demonstrates increased nasal carriage of staphylococci and a correlation between nasal carriage and relapse. ${ }^{10}$ However, the role of nasal carriage has been explored in parallel with the European Vasculitis Study Group (EUVAS) trials with a much less clear-cut picture emerging, although the number of swabs taken were far less (D. Jayne, unpublished observations). A suggestion that staphylococcal toxic-shock-syndrome-toxin may play a part in $W^{55}$ is not supported by the nature of the disease, whose time frame and pathology are quite unlike that seen in an accepted superantigen-induced disease, such as the toxic shock syndrome or probable superantigeninduced disease, such as the vasculitis Kawasaki syndrome. $^{56}$ A more recent initially exciting finding provided evidence for molecular mimicry between the human LAMP-2 epitope (a common ANCA specificity) and bacterial adhesion FimH derived from many Gramnegative organisms. ${ }^{11}$ This quite compelling hypothesis remains in limbo as the serological studies have been proven to be difficult to repeat in other laboratories. ${ }^{57}$

An observation that a patient who received trimethoprim-sulphamethoxazole (TMP-SX) for a urinary tract infection with Escherichia coli had an apparent coincident improvement in his or her intercurrent WG, leading to TMP-SX being used for induction therapy in WG, a situation where, except perhaps for limited nasal disease, its efficacy is suspect, and for maintenance therapy, where it appears to have an adjunctive role. ${ }^{58}$ While this may represent an antimicrobial effect, there is no proof of that, and TMP-SX may also have intrinsic immunosuppressive properties. ${ }^{59}$

\section{Nature - genetics}

All three syndromes are rare in children, occurring in the middle aged to elderly, suggesting that genetic effects are not particularly strong. Indeed, a study looking for familial clustering found that unlike many typical autoimmune syndromes this was rare. ${ }^{60}$ The standard genetic study nowadays is a genome-wide association study (GWAS). Such a study has been performed but not yet published, and this review will examine some welldefined disease association, largely case-control studies looking at genes selected as potential candidates because of experience with other diseases. Most susceptibility genes in autoimmune diseases encode a phenotype that interacts with the immune system, some affect the putative autoantigens. In considering susceptibility genes, consideration will be given as to their possible mode of action, after all, it is such pathophysiological studies that will give us the complete picture hinted at by GWAS.

Known genetic associations include genes that encode proteins known to be important in T-cell activation. All of these genetic associations are quite weak, generally with odds ratios of 2-3. There are some major histocompatibility complex class II linkages; DP1*0401 with WG and MPA in Caucasians and DRB ${ }^{*} 0901$ with MPA in Japanese and DRB4 with CSS. ${ }^{61-64}$ An allelic form of CTLA-4, a negative regulator of T-cell activation, encodes a less efficient protein which would be associated with persistent immune activity. ${ }^{62}$ In contrast, the gene (T1858) encoding the lymphoid tyrosine phosphatise (PTPN-22) encodes an allelic variant LYP*W620, increased in WG and MPA, which is a less effective regulator of T-cell activity, unless one speculates that this factor is more active in regulatory $\mathrm{T}$ cells, its actions seem at odds with expectations. There remains some contention about the 
mechanism of this protein in human cells. ${ }^{65}$ There is also an association of variants of CD226 that would increase integrin-mediated activation of naive cells. ${ }^{62} \mathrm{~A}$ more detailed examination of the DP region on chromosome 6 has shown an independent association with a gene encoding retinoid $X$ receptor $B$, which is involved in the transport of vitamin $\mathrm{D}$ across the nuclear membrane. ${ }^{61}$ No relevant functional defects have yet been described.

There is also an association with genes and their products involved in inflammation. WG is associated with the dysfunctional alpha-1 antitrypsin alleles, Z and S. ${ }^{66}$ The association with increased copy number of FCR3B is, however, disputed. ${ }^{62}$

A powerful new genetic contribution to autoimmune disease has been the recognition of genetically determined qualitative or quantitative differences in target antigens. This has only been explored to a limited extent, but patients with anti-PR3 related vasculitis (generally WG) who have high surface expression of PR3 on neutrophils have a higher incidence of relapse. ${ }^{62}$

\section{Synthesis}

Based on the environmental and genetic findings described so far, animal models and ex vivo studies in AASV, a model that accounts for the current known facts has been proposed by a number of groups. ${ }^{6,7}$ Several assumptions appear to have been made in these reviews which can be challenged. Firstly, although the evidence from both animal models and passive transplacental acquisition of transient MPA that anti-MPO-ANCA play a role in the pathogenesis of MPA is quite strong, neither convincing animal models nor a human experiment of nature have been documented for anti-PR3. ${ }^{6}$ A role of the diagnostic or marker antibodies in actual disease pathogenesis cannot be assumed. Secondly, while there is broad agreement that infectious agents may trigger attacks, the concept that specific agents, such as $S$. aureus or Gram-negative organisms, generally are involved remains under question. ${ }^{54-57}$ Finally, proposed models include a degree of homogeneity in regard to the pathogenesis of the three syndromes that is not justified by the literature quoted in support and indeed quite different, albeit overlapping mechanisms may be expected. ${ }^{6,8}$ At this time, the dilemma is most readily resolved by separating out the pathogenesis of granulomas, seen in WG and CSS from necrotising vasculitis involving small arteries, arterioles, capillaries and venules, common to all three syndromes. ${ }^{6,8}$ Current evidence suggests that the vasculitic lesions involve neutrophil activation, probably abetted by ANCA and consequent neutrophil enzyme and other product-mediated vascular damage ${ }^{6}$ As $\mathrm{T}$ helper (Th) 17 cells predominate in the capacity to recruit neutrophils, these $\mathrm{T}$ cells are probably involved, and if antibody production is really integral to the development of vasculitis, then Th2 cells are presumably involved. ${ }^{6}$ Granulomas are generally regarded as a product of disturbed innate and cellular immunity, and in the context of WG and potentially CSS with overactive Thl and Thl7 cells and a reduction in numbers and/or activity of regulatory $\mathrm{T}$ (Treg) cells. ${ }^{67,68}$ The known environmental factors can be reconciled with this model. The impact of low vitamin $\mathrm{D}$ would be manifest through increased Thl and Th 17 and decreased Tregs and associated with granuloma formation, consistent with the latitudinal gradient seen with both WG and CSS, but not MPA, where there are no granulomas. ${ }^{43}$ Silica exposure has been associated with decreased Tregs and increased Thl7 and could play a role in all three syndromes. ${ }^{44}$ The genetic influences are relatively weak but appear to act to upregulate lymphocyte activity or enhance neutrophil-mediated inflammation. ${ }^{69}$ The action of the PTPN-22 is difficult to reconcile as the action of the associated LYP*W620 allele is associated with reduced T-cell receptor-mediated signalling and remains subject to further research, particularly as this is an important risk gene in a number of disparate autoimmune diseases. ${ }^{65}$ The concept of quantitative thresholds for immune cell signalling has allowed an understanding of how multiple genetic factors of a relatively small effect may combine to create a state of susceptibility to autoimmunity. ${ }^{70}$

\section{References}

1 Jenette JC, Falk RJ. Nosology of primary vasculitis. Curr Opin Rheumatol 2007; 19: 10-16.

2 Kallenberg CGM. Antineutrophil cytoplasmic autoantibody-associated small vessel vasculitis. Curr Opin Rheumatol 2007; 19: 17-24.

3 Hunder GG, Arend WP, Bloch DA, Calabrese LH, Fauci AS, Fries JF et al. The American College of
Rheumatology 1990 criteria for the classification of vasculitis: introduction. Arthritis Rheum 1990; 33 1065-67.

4 Jennette JC, Falk RJ, Andrassy K, Bacon PA, Churg J, Gross WL et al. Nomenclature of systemic vasculitides: proposal of an international consensus conference. Arthritis Rheum 1994; 37 : 187-92.

5 Watts RA, Suppiah R, Merkel PA, Luqmani R. Systemic vasculitis - is it time to reclassify? Rheumatology (Oxford) 2011; 50: 643-5.

6 Kallenberg CGM. Pathophysiology of ANCA-associated small velssel vasculitis. Curr Rheumatol Rep 2010; 12: 399-405.

7 Wilde B, van Paassen B, Witzke O, Tervaert JWC. New pathophysiological insights and treatment of ANCA-associated vasculitis. Kidney Int 2011; 79: 599-612.

8 de Lind van Wijngaarden RAF, van Rijn L, Hagen EC, Watts RA, 
Gregorini G, Tervaert JWC et al. Hypotheses on the etiology of antineutrophil cytoplasmic autoantibody-associated vasculitis: the cause is hidden, but the result is known Clin J Am Soc Nephrol 2008; 3: 237-52.

9 Gibelin A, Maldini C, Mahr A. Epidemiology and etiology of Wegener granulomatosis, microscopic polyangiitis, Churg-Strauss syndrome, Goodpasture syndrome: vasculitides with frequent lung involvement. Semin Respir Crit Care Med 2011; 32: 264-73.

10 Popa ER, Cohen Tervaert JW. The relationship between Staphylococcus aureus and Wegener's granulomatosis: current knowledge and future directions. Intern Med 2003; 42: 771-80.

11 Kain R, Exner M, Brandes R, Ziebemayr R, Cunningham D, Davidovits A et al. Molecular mimicry in pauci-immune focal necrotizing glomerulonephritis. Nat Med 2008; 14: 1088-96.

12 Reinhold-Keller E, Zeidler A, Gutfleisch J, Peter HH, Rapse HH, Gross WL. Giant cell arteritis is more prevalent in urban than rural populations: results of an epidemiological study of primary systemic vasculitides in Germany. Rheumatology (Oxford) 2000; 39: 1396-402.

13 Reinhold-Keller E, Herlyn K, Wagner-Bastmeyer R, Gutfleisch J, Peter HH, Raspe HH et al. No difference in the incidences of vasculitides between north and south Germany: first results of the German vasculitis register. Rheumatology (Oxford) 2002; 41: 540-49.

14 Reinhold-Keller E, Herlyn K, Wagner-Bastmeyer R, Gross WL. Stable incidence of primary systemic vasculitides over five years: results from the German vasculitis register. Arthritis Rheum 2005; 53: 93-9.

15 Carruthers DM, Watts RA, Symmons DPM, Scott DGI. Wegener's granulomatosis - increased incidence or increased recognition? Br J Rheumatol 1996; 35: 142-5.

16 Watts RA, Lane SE, Bentham G, Scott DGI. Epidemiology of systemic vasculitis. A ten year study in the United Kingdom. Arthritis Rheum 2000; 43: 414-19.

17 González-Gay MA, García-Porrúa C. Systemic vasculitis in adults in northwest Spain, 1988-1997. Clinical and epidemiologic aspects. Medicine (Baltimore) 1999; 78: 292-308.
18 Gonzalez-Gay MA, Garcia-Porrua C, Guerrero J, Rodriguez-Ledo P, Llorca J. The epidemiology of the primary systemic vasculitides in north-west Spain: implications of the Chapel Hill Consensus Conference definitions. Arthritis Rheum 2003; 49: 388-93.

19 Knight A, Ekbom A, Brandt L, Askling J. Increasing incidence of Wegener's granulomatosis in Sweden, 1975-2001. J Rheumatol 2006; 33: 2060-63.

20 Koldingsnes W, Nossent H. Epidemiology of Wegener's granulomatosis in northern Norway. Arthritis Rheum 2000; 43: 2481-7.

21 Dadoniene J, Kirdaite G, Mackiewicz Z, Rimkevicius A, Haugeberg G. Incidence of primary systemic vasculitis in Vilnius: a university hospital population based study. Ann Rheum Dis 2005; 64: 335-6.

22 Zeft A, Schlesinger M, Weiss N, Emery H. Case control study of ANCA associated vasculitis in Western Montana. Arthritis Rheum 2005; 52(Suppl 9): S648.

23 Sanchez-Torres AA, Acevedo-Vasquez EM, Sanchez-Schwartz CG, Pastor-Asurza CA, Perich-Campos RA, Alfaro-Lozano JL et al. Epidemiology of the primary systemic vasculitides in a Latin-American population. Clin Exp Rheumatol 2007; 25(Suppl 44): S95.

24 Ormerod AS, Cook MC. Epidemiology of primary systemic vasculitis in the Australian Capital Territory and south-eastern New South Wales. Intern Med J 2008; 38: 816-23.

25 Fujimoto S, Uezono S, Hisanaga S, Fukedome K, Koyabayashi S, Suzuki K et al. Incidence of ANCA-associated primary renal vasculitis in the Miyazaki prefecture: the first population-based, retrospective, epidemiologic survey in Japan. Clin J Am Soc Nephrol 2006; 1: 1016-22.

26 El-Reshaid K, Kapoor MM, El-Reshaid W, Madda JP, Varro J. The spectrum of renal disease associated with microscopic polyangiitis and classic polyarteritis nodosa in Kuwait. Nephrol Dial Transplant 1997; 12: 1874-82.

27 O'Donnell JL, Stevanovic VR, Frampton C, Stamp LK, Chapman PT. Wegener's granulomatosis in New Zealand: evidence for a latitude dependent gradient. Intern Med J 2007; 37: 242-6.

28 Haugeberg G, Bie R, Benvold A, Storm Larsen A, Johnsen V. Primary vasculitis in a Norwegian community hospital: a retrospective study. Clin Rheumatol 1998; 17: 364-8.

29 Mahr A, Guillevin L, Poissonnet M, Ayme S. Prevalences of polyarteritis nodosa, microscopic polyangiitis, Wegener's granulomatosis, and Churg-Strauss syndrome in a French urban multi-ethnic population in 2000: a capture-recapture estimate. Arthritis Rheum 2004; 51: 92-9.

30 Mohammad AJ, Jacobsson LTH, Mahr AD, Sturfelt G, Segelmark M. Prevalence of Wegener's granulomatosis, microscopic polyangiitis, polyarteritis nodosa and Churg-Strauss syndrome within a defined population in southern Sweden. Rheumatology(Oxford) 2007; 46: 1329-37.

31 Cotch MF, Hoffman GS, Yerg DE, Kaufman GI, Targonski P, Kaslow RA. The epidemiology of Wegener's granulomatosis. Arthritis Rheum 1996; 39: 87-92.

32 Gibson A, Stamp LK, Chapman PT, O'Donnell JL. The epidemiology of Wegener's granulomatosis and microscopic polyangiitis in a southern hemisphere region. Rheumatology (Oxford) 2006; 45: 624-8.

33 Watts RA, Scott DGI, Fujimoto S, Kobayashi S, Suzuki K, Shigeto S et al. Epidemiology of renal ANCA-associated vasculitis in the UK and Japan. Clin Exp Rheumatol 2007; 25(Suppl 44): S95.

34 Jacobson DL, Grange SJ, Rose NR, Graham NMH. Epidemiology and estimated population burden of selected autoimmune diseases in the United States. Clin Immunol Immunopathol 1997; 84: 223-43.

35 Falk RJ, Hogan S, Carey TS, Jennette JC. Clinical course of anti-neutrophil cytoplasmic autoantibody-associated glomerulonephritis and systemic vasculitis. The Glomerular Disease Collaborative Network. Ann Intern Med 1990; 113: 656-63.

36 Lane SE, Scott DGI, Heaton A, Watts RA. Primary renal vasculitis in Norfolk - increasing incidence or increasing recognition? Nephrol Dial Transplant 2000; 15: 23-7.

37 Tidman M, Orlander R, Svalander C, Danielsson D. Patients hospitalised because of small vessel vasculitides with renal involvement in the period 1975-1995: organ involvement, anti-neutrophil cytoplasmic antibodies 
patterns, seasonal attack rates and fluctuation of annual frequencies. J Intern Med 1998; 244: 133-41.

38 Watts RA, Mooney J, Mukhtyar C, Skinner J, MacGregor A, Scott DGI. Contrasting epidemiology of WG and MPA. Clin Exp Immunol 2011; 164(Suppl 1): 73 .

39 Raynauld JP, Bloch DA, Fries JF. Seasonal variation in the onset of Wegener's granulomatosis, polyarteritis nodosa and giant cell arteritis. $J$ Rheumatol 1993; 20: 1524-6.

40 Mahr A, Artigues N, Coste N, Aouba A, Pagnoux C, Guillevin L et al. Seasonal variations in onset of Wegener's granulomatosis: increase in summer? $J$ Rheumatol 2006; 33: 1615-22.

41 Lane SE, Watts RA, Scott DGI. Seasonal variations in onset of Wegener's granulomatosis: increased in summer? $J$ Rheumatol 2007; 34: 889-90.

42 Gatenby PA, Lucas RM, Engelsen O, Ponsonby A-L, Clements M. Antineutrophil cytoplasmic antibody-associated vasculitides: could geographic patterns be explained by ambient ultraviolet radiation? Arthritis Rheum (Arthritis Care Res) 2009; 61: 1417-24.

43 Peelen E, Knippenberg S, Muris A-H, Thewisson M, Smolders J, Tervaert JWC et al. Effects of vitamin D on the peripheral adaptive immune system: a review. Autoimmun Rev 2011; 10: 733-43.

44 Steenland K. One agent, many diseases: exposure-response data and comparative risks of different outcomes following silica exposure. Am J Ind Med 2005; 48: 16-23.

45 Yashiro M, Muso E, Itoh-Ihara T, Oyama A, Hashimoto K, Kawanura T et al. Significantly high regional morbidity of MPO-ANCA-related angiitis and/or nephritis with respiratory tract involvement after the 1995 great earthquake in Kobe(Japan). Am J Kidney Dis 2000; 35: 889-95.

46 Cuellar ML. Drug-induced vasculitis. Curr Rheumatol Rep 2002; 4: 55-9.

47 Yu F, Chen M, Gao Y, Wang SX, Zou WZ, Zhao MH et al. Clinical and pathological features of renal involvement in propylthiouracilassociated ANCA-positive vasculitis. Am J Kidney Dis 2007; 49: 607-14.
48 Short AK, Lockwood CM. Antigen specificity in hydralazine associated ANCA positive systemic vasculitis. Q J Med 1995; 88: 775-83.

49 Gao Y, Chen M, Ye H, Guo XH, Zhao MH, Wang HY. The target antigens of antineutrophil cytoplasmic antibodies (ANCA) induced by propylthiouracil. Int Immunopharmacol 2007; 7: 55-60.

50 Jamaleddine G, Diab K, Tabbarah Z, Tawil A, Arayssi T. Leukotiene antagonists and the Churg-Strauss syndrome. Semin Arthritis Rheum 2002; 31: 218-27.

51 Kranke B, Aberer W. Macrolide-induced Churg-Strauss syndrome in patient with atopy. Lancet 1997; 350: 1551-2.

52 Hubner C, Dietz A, Stremmel W, Stiehl A, Andrassy H. Macrolide-induced Churg-Strauss syndrome in a patient with atopy. Lancet 1997; 350: 563.

53 Dietz A, Hubner C, Andrassy K. Macrolide induced vasculitis (Churg-Strauss syndrome). Laryngorhinootologie 1998; 77: 111-14.

54 Rodriguez-Pla A, Stone JH. Vasculitis and systemic infections. Curr Opin Rheumatol 2006; 18: 39-47.

55 Popa ER, Stegeman CA, Abdulahad B, van der Meer B, Manson WM, Bos NA et al. Staphylococcal toxic-shocksyndrome-toxin- 1 as a risk factor for disease relapse in Wegener's granulomatosis. Rheumatology (Oxford) 2007; 46: 1029-33.

56 Leung DY, Schlievert PM, Meissner HC. The immunopathogenesis and management of Kawasaki syndrome. Arthritis Rheum 1998; 41: 1538-47.

57 Preston GA, Roth AJ, Brown MC, Badhwar AK, Chung HC, McGregor JG et al. Is LAMP-2 a target of ANCA? Clin Exp Immunol 2011; 164(Suppl 1): 46.

58 Stegman CA, Tervaert JW, de Jong PE, Kallenberg CG. Trimethoprimsulfamethoxazole (co-trimoxazole) for the prevention of relapses of Wegener's granulomatosis. Dutch Co-Trimoxazole Wegener Study Group. N Engl J Med 1996; 335: 16-20.

59 Hamidou MA, Audrain M, Ninin E, Robillard N, Muller J-Y, Bonneville M. Staphylococcus aureus, T cell repertoire, and Wegener's granulomatosis. Joint Bone Spine 2001; 68: 373-7.

60 Knight A, Sandin S, Askling J. Risks and relative risks of Wegener's granulomatosis among close relatives of patients with the disease. Arthritis Rheum 2008; 58: 302-7.

61 Heckmann M, Holle JU, Arning LO,

Knaup S, Hellmich B, Nothnagel M et al. The Wegener's granulomatosis quantitative trait locus on chromosome $6 \mathrm{p} 21.3$ as characterised by tagSNP typing. Ann Rheum Dis 2008; 67: 972-9.

62 Wieczorek S, Holle JU, Epplen JT. Recent progress in the genetics of Wegener's granulomatosis and Churg-Strauss syndrome. Curr Opin Rheumatol 2010; 22: 8-14.

63 Tsuchyia N, Kobayashi S, Kawasaki A, Kyoogoku C, Arimura Y, Tokunaga K et al. Genetic background of Japanese patients with antineutrophil cytoploasmic antibody associated vasculitis: association of HLA-DRB $1 * 0901$ with microscopic angiitis. J Rheumatol 2003; 30: 1534-40.

64 Vaglio A, Martorana D, Maggiore U, Grasselli C, Zanetti A, Pesci A et al. HLA-DRB4 as a genetic risk factor for Churg-Strauss syndrome. Arthritis Rheum 2007; 56: 3159-66.

65 Vang T, Miletic AV, Arimura Y, Tautz L, Rickert RC, Mustelin T. Protein tyrosine phosphatases in autoimmunity. Аnnu Rev Immunol 2008; 26: 29-55.

66 Mahr AD, Edberg JC, Stone JH, Hoffman GS, StClair EW, Specks U et al. Alphl-antitrypsin deficiency related alleles $\mathrm{Z}$ and $\mathrm{S}$ and the risk of Wegener's granulomatosis. Arthritis Rheum 2010; 62: 3760-67.

67 Lamprecht P, Wieczorek S, Epplen JT, Ambrosch P, Kallenberg CGM. Granuloma formation in ANCA-associated vasculitides. APMIS 2009; 117(Suppl 127): 32-6.

68 Morgan MD, Day CJ, Piper KP, Khan N, Harper L, Moss PA et al. Patients with Wegener's granulomatosis demonstrate a relative deficiency and functional impairment of T-regulatory cells. Immunology 2010; 130: 64-73.

69 Willcocks LC, Lyons PA, Rees AJ, Smith KGC. The contribution of genetic variation and infection to the pathogenesis of ANCA-associated systemic vasculitis. Arthritis Res Ther 2010; 12: 202-13.

70 Cho JH, Gregersen PK. Genomics and the multifactorial nature of human autoimmune disease. $N$ Engl J Med 2011; 365: 1612-23. 